This is the original submission to the journal with all revisions after the peer review and proof-reading. Supplying this version ("version 2") to the institution's repository is in accordance with the SAGE publication guidelines.

\title{
Using smartphone-based applications (apps) in workplace health promotion: The opinion of German and Austrian leaders.
}

\author{
Dunkl, Anita
}

Department of Psychology, University of Graz, Universitätsplatz 2, 8010 Graz, Austria. E-mail: anita.dunkl@uni-graz.at

Jiménez, Paul

Department of Psychology, University of Graz, Universitätsplatz 2, 8010 Graz, Austria. E-mail: paul.jimenez@uni-graz.at

\section{Corresponding Author:}

Dunkl, Anita, Department of Psychology, University of Graz, Universitätsplatz 2, 8010 Graz, Austria. Phone: +43/316/380-5102. E-mail: anita.dunkl@uni-graz.at

Suggested citation:

Dunkl, A. \& Jiménez, P. (2017). Using smartphone-based applications (apps) in workplace health promotion: The opinion of German and Austrian leaders. Health Informatics Journal, 23(1), 44-55. doi: $10.1177 / 1460458215623077$

(c) [2017] SAGE Publishing

Original version of the article online available under:

http://jhi.sagepub.com/content/early/2016/01/28/1460458215623077.full.pdf+html

DOI: $10.1177 / 1460458215623077$ 


\begin{abstract}
Reaching the actual target group for a web-based health promotion project turns out to be a difficult task. In this paper, individual and organizational factors which can influence the decision of using apps in workplace health promotion are analyzed. Further, we analyzed the opinion about feedback possibilities of apps in WHP. A study with 438 leaders was conducted, as leaders can be seen as a key factor in the success of health promotion projects. The results showed that younger leaders and leaders with a more positive attitude towards workplace health promotion are more likely to use an app. Further, leaders with a positive attitude are more interested in expert feedback than in instant feedback received from an app.
\end{abstract}

Keywords: application, feedback, leadership, target group, workplace health promotion 


\section{Introduction}

Smartphones have, little by little, invaded our modern everyday life and are already an established means to keep in touch with our family and friends all around the globe. But the pocket-sized supercomputers are not only an aid regarding communication, but have also gained importance as a reliable source of information via internet connection. Furthermore, there is a variety of smartphone applications (short: apps) to choose from, ranging from simple video games to pass the time to reliable assistants to help us face and conquer everyday tasks and challenges.

In line with this increased availability and usage of smartphones, apps for health promotion practices and health outcomes are advancing. Despite the increased number of developed health apps which can be downloaded at the app store, little scientific research has been done about apps for health promotion practices and health outcomes and there is even less research about psychological interventions in the organizational context. ${ }^{1,2}$ Some notable publications in the development and analysis of apps in the organizational context include apps for individual stress prevention and leadership development, ${ }^{3,4,5,6}$ but there is a lack of holistic workplace health promotion (WHP) apps which can be implemented in the organizational process.

Reaching the right target group and raising participation rates is one major challenge in WHP. This challenge is the same for app-based projects in WHP. Both individual and organizational differences are able to influence participation, such as gender, age, health status, experience or size of organization. ${ }^{7,8,9,10}$ Therefore, the aims of this paper are (1) to identify individual and organizational aspects which might influence the decision of using an app in WHP and (2) analyze the opinion about 
feedback possibilities of apps in WHP. More specifically, we investigate the opinion of leaders, as leaders can be seen as a major key factor in the success of WHP projects. ${ }^{11,12}$

\subsection{Smartphone apps and health promotion}

Apps in health promotion have multiple benefits, such as being relatively inexpensive, reaching a large number of individuals even in remote places, supporting highly stigmatized groups without exposing them, sharing health information on social media, 24-hour accessibility, providing updated content to the app any time, implementing visual materials (e.g. graphs, videos) and repeating lectures/trainings as often as wanted. $3,4,6,13,14,15,16$

Another major advantage is delivering instant feedback and support. ${ }^{4,15}$ Instant feedback helps participants monitoring their personal progress and can motivate participants to proceed with health apps. In their guidelines for internet interventions, Proudfoot et al. stated that professional support should be included to assist an online intervention. ${ }^{17}$ This professional support can be delivered frequently by qualified health professionals by using e-mail, forums, audio chat, webcam or even face-to-face support. Ritterband et al. also suggested that instant feedback and support can be provided in many ways, e.g. personalized e-mails, instant messaging communication or even phone and face-to-face meetings. ${ }^{15}$

However, with external support via phone or face-to-face meetings, the reach of apps will be reduced, the costs increase, and the app will be more difficult to organize. ${ }^{18}$ On the other hand, a totally unguided program has more drop-out rates and even can raise ethical issues, such as failing treatments, negative side effects or misinterpretation 
of the instant feedback on the screen. ${ }^{16,18}$ Further, a program without any experts behind is lacking quality and will be less effective. ${ }^{19}$

A major challenge is quality assurance, as currently nearly everybody is allowed to develop an app. ${ }^{20}$ Another potential risk is data security and privacy. ${ }^{1,21}$ The user's lack of technical skills or knowledge related to the use of new media is an additional barrier that can prevent persons to try app-based health promotion programs. ${ }^{20}$

Reaching the right target group is another critical aspect that has to be noted. Health apps are mainly used by those individuals already supporting a healthy lifestyle, ${ }^{22,23}$ a point which can be found also in other health promotion activities. ${ }^{10,24}$ This is critical, especially when it comes to WHP, where the organization puts time, money and effort into efficient, successful health promotion activities.

\subsection{Individual and organizational differences in WHP programs}

As previously mentioned, healthier people have higher participation levels in WHP programs. Additionally, women are shown to participate more often in health intervention programs than men, ${ }^{7,10,25}$ but there is also evidence that with offering the right activities, men and women are participating alike. ${ }^{9}$ Next to gender, there seems to be a trend where younger employees have the highest and elder employees have the lowest participation level in WHP programs. ${ }^{9}$ However, when it comes to long-term participation, older participants are more likely to participate in follow-up programs. ${ }^{24,26}$

Further, WHP programs are usually conducted in larger enterprises. In smaller organizations, the owner usually is responsible for all management functions and additionally managing health programs therefore is less interesting. Moreover, the benefits of WHP activities are less obvious in the short term, as problems such as health 
issues or accidents rarely occur in small organizations. ${ }^{8,27}$ However, there is evidence that although larger companies usually organize more health promotion activities, the participation levels in smaller organizations are higher. ${ }^{9}$

Several methods have been suggested to increase participation rates, such as individually tailored-interventions, personalized mails or giving instant individual feedback. ${ }^{2,25,28,29}$ For health promotion at the workplace, recruitment via company counselors or in particular leaders should be considered to raise participation. ${ }^{11,12,22}$ Successful WHP projects are presented by leaders encouraging their employees to adopt a healthy lifestyle and give information about health-relevant issues. ${ }^{30}$ Furthermore, leaders who illustrate the benefits of a WHP program are able to influence the participation level positively. ${ }^{31}$ Therefore, leaders are the promoters of WHP and must be seen as the major target group when implementing app- or web-based health promotion programs at the workplace.

\subsection{Research questions}

In the present paper, we want to identify individual and organizational aspects which might influence the decision of using an app in WHP and analyze the opinion about feedback possibilities of apps in WHP. For this purpose, a study with leaders is conducted, as leaders can be seen as a major key factor in the success of WHP projects. ${ }^{11,12}$ Referring to the current status of research, following hypotheses were stated:

1) Female leaders have a more positive opinion of using apps in WHP and their feedback possibilities. 
2) Younger leaders have a more positive opinion of using apps in WHP and their feedback possibilities.

3) Leadership experience is positively related to acceptance of apps and their feedback options in WHP, as experienced leaders have the information and skills to conduct and promote health promotion projects at the workplace.

4) Similar to the findings that healthier individuals more often participate in health promotion activities we propose that leaders with a more positive attitude towards health promotion are more interested to use an app and have a more positive opinion for app-related feedback.

5) Working in a larger organization is positively related to a higher acceptance of apps in WHP and its feedback possibilities.

6) Having a higher number of direct subordinates is positively related to a higher acceptance of apps in WHP and its feedback possibilities.

\section{Material and methods}

\subsection{Recruitment and selection}

Austrian and German leaders were invited to participate in an online study. In this study, we defined leaders as persons who assume responsibility for one or more employees in a lower hierarchy.

In cooperation with a German market research company, the participants were invited by sending out e-mails. The participants had to fulfill the requirement of currently having a leading position; otherwise they were excluded at the beginning of the survey. All-in-all 884 participants declared their interest to be part of this study. Out of this sample, 418 participants had to be excluded as they did not have a leading 
position; 28 participants cancelled their participation after answering only a few questions. In the end, a sample of 438 leaders who filled-in all questionnaires could be used for this study.

\subsection{Participants}

In this sample of 438 leaders, $64.2 \%$ were working in Germany and $35.8 \%$ were working in Austria; $29 \%$ were female and $71 \%$ are male. $42.5 \%$ were 40 years or younger, $34.9 \%$ were between 41 and 50 years old and $22.6 \%$ were older than 51 years. They worked in different business sectors, working mostly in the business sectors service/consulting (28.3\%), manufacturing (12.3\%), commerce $(12.3 \%)$, health care (6.6\%), and insurance (6.4\%). Company sizes ranged from one to nine employees (26.2\%), ten to 49 employees (17.1\%), 50 to 199 employees (16.8\%) and 200 employees and more (39.9\%).

The leaders mostly worked in middle or first-line management (68.7\%); 31.3\% were CEOs. Most of the leaders (38.2\%) had their leading position for longer than ten years, $28.8 \%$ had their leading position for 5 to ten years and $22.7 \%$ for two to five years. The number of direct subordinates varied, ranging from only one subordinate (18.7\%), two to five subordinates $(29.5 \%)$, six to ten subordinates $(19.2 \%)$, and more than ten subordinates $(32.6 \%)$.

\subsection{Measurements}

Next to the sociodemographic data (gender, age, leadership experience, organization size, and number of direct subordinates), the acceptance of using apps in WHP and feedback possibilities of apps were measured with scales previously developed for this study. All items are listed in table 1. 
The attitude towards workplace health promotion in general was measured with six items. These six items can be combined into one scale "positive attitude towards workplace health promotion (WHP)". The questions could be answered on a five-point Likert scale from 1 (I disagree) to 5 (I agree).

The acceptance of using apps in workplace health promotion was measured with two items (see table 1). These two items could be answered on a five-point Likert scale from 1 (I disagree) to 5 (I agree). These two items are combined into one scale "acceptance of using apps in workplace health promotion (WHP)".

Attitude towards feedback was measured with five items. These items can be categorized in two scales: 1) expert-feedback (three items) and 2) feedback from new media (two items). Answer scale was a five-point Likert scale ranging from 1 (I disagree) to 5 (I agree).

Feedback possibilities from an app were measured referring to three possible WHP aspects: physical fitness, mental fitness and nutrition. Twelve items could be answered on a five-point Likert scale ranging from 1 (I disagree) to 5 (I agree). There were four similar answers for each of the three aspects physical fitness, mental fitness and healthy nutrition (see table 1). The twelve items and can be categorized in four scales: 1) individual feedback, 2) analyses of results, 3) advice/suggestions, and 4) sharing results. 


\section{Results}

\subsection{Descriptive Statistics}

Means, standard deviations, internal consistencies and correlations of the scales can be found in table 2. Internal consistencies of all study variables are high, ranging between .80 and .95 , with the exception of feedback from new media (.51).

As for the individual aspects, significant correlates can be found for age and positive attitude towards WHP. Age is positively correlated with expert feedback (.16) and negatively correlated with feedback from new media (-.13), individual feedback ($.12)$, statistical results (-.11) and sharing results (-.16). Positive attitude towards WHP shows a strong positive correlation with expert-feedback (.39) and moderate to low correlations with acceptance of apps in WHP (.26), feedback from new media (-.16), and advice/suggestions (.13).

For the organizational aspects, only low to zero correlations with the outcome variables can be found, showing the highest correlation between size of organization and positive attitude towards WHP (.16).

Insert table 2

\subsection{Individual and organizational differences and acceptance of apps in WHP /} feedback possibilities

A hierarchical multiple linear regression analysis was conducted separately for all outcome criteria. Table 3 presents the two steps of the analysis. The individual predictors gender, age, leadership experience and positive attitude towards WHP 
(hypothesis 1, 2, 3, and 4) were stepped into the equation first. This step was significant for all outcomes: acceptance of apps in WHP $(\mathrm{F}(4,435)=10.453, \mathrm{p}<.0001)$, expertfeedback $(\mathrm{F}(4,435)=23.335, \mathrm{p}<.0001)$, feedback from new media $(\mathrm{F}(4,435)=23.335$, $\mathrm{p}<.0001)$, individual feedback $(\mathrm{F}(4,436)=2.472, \mathrm{p}<.05)$, analyses of results $(\mathrm{F}(4,436)=$ 3.016, $\mathrm{p}<.05)$, advice/suggestions $(\mathrm{F}(4,436)=3.735, \mathrm{p}<.01)$, and sharing results $(\mathrm{F}(4,436)=3.365, \mathrm{p}<.01)$. The second step of the model included the organizational predictors size of organization (hypothesis 5) and number of direct subordinates (hypothesis 6). For all outcome variables, this second step did not significantly add to the explained variance.

Age and positive attitude towards WHP in general were the most important predictors. In detail, gender (hypothesis 1) does not show any significant result, which was not expected in our hypotheses. As assumed in hypothesis 2, age is negatively associated with acceptance of apps in WHP and feedback possibilities of an app. In contrast to our hypothesis, leadership experience did not show any significant association with acceptance of apps or feedback options (hypothesis 3). In line with hypothesis 4 , leaders with a more positive attitude towards WHP are more interested to use an app. Hypothesis 5 and 6 also could not be supported, as the size of the organization and the number of direct subordinates did not show a significant relation with acceptance of apps and feedback options.

In table 3, the standardized regression coefficients as well as p-values and adjusted $\mathrm{R}^{2}$ from the last step are presented.

Insert table 3 


\section{Discussion}

In the present paper, we aimed to (1) identify individual and organizational aspects which might influence the decision of using an app in WHP and (2) analyze the opinion about feedback possibilities of apps in WHP.

Our first hypothesis, that female leaders are more likely to use an app and their feedback possibilities, was not supported. In our findings, gender does not show any significant effect. This non-significant result might be influenced by a common gender stereotype, where men are more open using new media and technical devices. Another explanation could be the fact that women are underrepresented in leading positions. In the present study, only $29 \%$ of the leaders were female. So this non-significant result could be an effect of an inhomogeneous group.

The second hypothesis, that younger leaders would have a more positive opinion of using apps and their feedback possibilities in WHP, was supported. The analysis shows that younger leaders would rather accept an app in WHP and use more of its feedback possibilities (individual feedback, analyses of results, advice/suggestions, sharing results). As younger individuals are shown to participate more often in WHP projects, ${ }^{9}$ this result was expected. Additionally, younger individuals are more familiar with new media such as smartphones and apps, as they are usually used by the younger generation.

As the third hypothesis states, leaders with a more positive attitude towards WHP are more interested to use an app but feedback is expected to be given by experts. Feedback from experts is also demanded by older leaders. This refers to quality issues that instant feedback is confronted with. A totally unguided program without human involvement can lead to high drop-out rates and smaller effects as employees are not 
provided with enough information and knowledge about health-relevant issues. ${ }^{19}$ Additionally, ethical issues are raised as feedback can be misinterpreted or might fail its purpose. ${ }^{16,18}$ As the statements of expert feedback do not exclude instant feedback this issue of quality has to be considered strongly. It can be concluded, that the expert's knowledge and skills are essential. This can be also seen in the scale "advice/suggestions from an app", as leaders with a more positive attitude towards WHP would wish this kind of feedback.

In line with past research, ${ }^{8,27}$ we expected an effect for organization size and number of direct subordinates, more specifically, that working in a larger organization and having a higher number of direct subordinates is positively related to a higher acceptance of apps in WHP. The findings could not support these assumptions. Larger companies are more willing to invest time and money in health promotion projects, ${ }^{8,27}$ but we did not find this result for app-based health promotion, as organization size and number of direct subordinates showed non-significant results. However, very large companies (5001+ employees) have usually fully adopted new technologies, using the internet for multiple purposes. ${ }^{32}$ Therefore, larger companies could be seen as a potential market for apps in WHP. This assumption has to be investigated more closely in future research. Further, leadership experience also shows no significant relation with acceptance of apps and their feedback possibilities in WHP.

Looking at the results, only small effects could be found, having low - although significant - adjusted $\mathrm{R}^{2}$. As we were able to collect a large sample of leaders in this study we can benefit from this advantage and see also these small effects. However, more studies including other influencing factors such as daily use of smartphones and 
apps or affinity for technology and mobile communications should be conducted to investigate possible effects.

\subsection{Limitations}

Data were collected online, which have the advantage of reaching a large number of participants. With this method, it was possible to collect a set of complete data without missing values from 438 leaders, allowing us to find even small effects. With this method, a selection bias could occur as our sample consists of leaders being familiar with the internet. Therefore it seems possible that with this recruitment method we asked leaders that already show a high affinity for technology. Generalizing the results to the total population might be difficult.

The participants were recruited with an online panel therefore it is possible that the sample in this study have more affinity for technology and mobile communications. However, this conclusion must be done with caution as we did not ask the participants about their frequency of using apps or other new media. Another important aspect which is not considered in this study is the style of leadership. Leaders that engage in a health-promoting leadership style are more likely to invest time and effort for health promotion practices. These aspects should be included in future research.

\subsection{Practical Implications and conclusion}

We could find that the most important aspect that leads to a higher acceptance of apps in WHP is a positive attitude towards WHP. Of course, a positive attitude means being aware of the need for prevention of risks at the workplace. Leaders that already 
engage in WHP activities can use apps to support health interventions. Apps could support in many ways, e.g., information about specific interventions (date, content) can be made available right away with the use of an app, or short questionnaires about the team's stress or motivation level can be used to get a feedback about the team's psychological state. Next studies should include possible features of an app in WHP to investigate the leaders' wishes and expectations.

The findings imply that using feedback possibilities of smartphone apps could be beneficial for WHP. The correlation analyses imply that leaders who would accept an app in WHP are also more interested in its feedback possibilities. The findings further suggest that feedback from experts could be an addition to automatic feedback. Especially when it comes to mental aspects, an automatic feedback without talking to "real" people can be critical, as automatic answers tend to be rather brief with less explanation. In line with this assumption, sharing these short automatic answers on social platforms may not be desirable, as they might lead to stigmatization. This is much more critical in a work-context, where colleagues and leaders might see the automatically generated feedback. In this sense, a web-based intervention with automatic feedback - either on the personal computer or on the smart phone - must be programmed in highest possible quality. Apps can help to sensitize people but in every case we need experts for every area, e.g. physical activities, mental fitness, and nutrition. These experts can be involved on many levels, such as planning the content of the program, developing understandable, non-stigmatizing feedback texts or being available for life-chats.

In the guidelines for internet intervention research of Proudfoot et al., professional and other support was already discussed. ${ }^{17}$ We should proceed to the next 
step also for internet interventions directly. Including "experts" in the process is an important quality criterion for every internet/software based application starting from the concept to the implementation. This is even more important when feedback possibilities are included, as the support of "real" people is needed especially when feedback of critical states are displayed. This will further raise the acceptance of using apps or web-related programs in WHP.

\section{Acknowledgement}

The authors want to thank the company Mikropis Holding, d.o.o, a partner in the EU Project 1646-002 A-LIFE, for sponsoring the recruiting of participants via the market research company. 


\section{References}

1. Kratzke C and Cox C. Smartphone Technology and Apps: Rapidly Changing Health Promotion. Int Electron J Health Educ 2012; 15: 72-82.

2. Ly KH, Asplund K and Andersson G. Stress management for middle managers via an acceptance and commitment-based smartphone application: A randomized controlled trial. Internet Interventions 2014; 1: 95-101. doi: 10.1016/j.invent.2014.06.003

3. Billings DW, Cook RF, Hendrickson A and Dove DC. A Web-Based Approach to Managing Stress and Mood Disorders in the Workforce. J Occup Environ Med 2008; 50: 960-968. doi: 10.1097/JOM.0b013e31816c435b

4. Hasson $\mathrm{H}$, Brown $\mathrm{C}$ and Hasson D. Factors associated with high use of a workplace web-based stress management program in a randomized controlled intervention study. Health Educ Res 2010; 24: 596-607. doi: doi:10.1093/her/cyq005

5. Ruwaard J, Lange A, Bouwan M, Broeksteeg J and Schrieken B. E-Mailed Standardized Cognitive Behavioural Treatment of Work-Related Stress: A Randomized Controlled Trial. Cog Behav Ther 2007; 36: 179-192. doi: $10.1080 / 16506070701381863$

6. Kawakami N, Takao S, Kobayashi Y and Tsutsumi A. Effects of Web-Based Supervisor Training on Job Stressors and Psychological Distress among Workers: A Workplace-Based Randomized Controlled Trial. J Occup Health 2006; 48: 38-34. 
7. Bradley KL, Robinson LM and Brannen CL. Adolescent help-seeking for psychological distress, depression, and anxiety using an Internet program. Int J Ment Health Prom 2014; 14: 23-34. doi: 10.1080/14623730.2012.665337

8. Champoux D and Brun JP. Occupational health and safety management in small size enterprises: an overview of the situation and avenues for intervention and research. Safety Sci 2003; 41: 301-318. doi: 10.1016/S0925-7535(02)00043-7

9. Robroek SJ, van Lenthe FJ, van Empelen P, et al. Determinants of participation in worksite health promotion programmes: a systematic review. Int J Behav Nutr Phys Act 2009. doi: 10.1186/1479-5868-6-26

10. Van Verheijden MW, Jans MP, Hildebrandt VH and Hopman-Rock M. Rates and Determinants of Repeated Participation in a Web-Based Behavior Change Program for Healthy Body Weight and Healthy Lifestyle. J Med Internet Res 2007; 9: e1. doi: 10.2196/jmir.9.1.e1

11. Dellve L, Skagert K and Vilhelmsson R. Leadership in workplace health promotion projects: 1- and 2-year effects on long-term work attendance. Eur J Public Health 2007; 17: 471-476. doi: 10.1093/eurpub/ckm004

12. Whitehead D. Workplace health promotion: the role and responsibility of health care managers. J Nurs Manage 2006; 14: 59-68. doi: 10.1111/j.13652934.2005.00599.x

13. Griffith F, Lindenmeyer A, Powell J, Lowe P and Thorogood M. Why Are Health Care Interventions Delivered Over the Internet? A Systematic Review of the Published Literature. J Med Internet Res 2006; 8: e10. doi: 10.2196/jmir.8.2.e10 
14. Househ M, Borycki E and Kushniruk A. Empowering patients through social media: The benefits and challenges. Health Informatics $J$ 2014; 20: 50-58.

15. Ritterband LM, Thorndike FP, Cox DJ, Kovatchev BP and Gonder-Frederick LA. A Behavior Change Model for Internet Interventions. Ann Behav Med 2009; 38: 18-27. doi: 10.1007/s12160-009-9133-4

16. Rozental A, Andersson G, Boettcher J, Ebert DD, Cujpers P, Knaevelsrud C, Ljotsson B, Kaldo V, Titov N and Carlbring P. Consensus statement on defining and measuring negative effects of Internet interventions. Internet Interventions 2014; 1: 12-19. doi: 10.1016/j.invent.2014.02.001

17. Proudfoot J, Klein B, Barak A, Carlbring P, Cuijpers P, Lange A and Andersson G. Establishing guidelines for executing and reporting Internet intervention research. Cog Behav Ther 2011; 40: 82-97. doi:

$10.1080 / 16506073.2011 .573807$

18. Donker T, van Straten A, Riper H, et al. Implementation of Internet-based preventive interventions for depression and anxiety: role of support? The design of a randomized controlled trial. Trials 2009. doi: 10.1186/1745-6215$10-59$

19. Shimazu A, Kawakami N, Irimajiri H, Sakamoto M and Amano S. Effects of Web-Based Psychoeducation on Self-Efficacy, Problem Solving Behavior, Stress Responses and Job Satisfaction among Workers: A Controlled Clinical Trial. J Occup Health 2005; 47: 405-413. doi: 10.1539/joh.47.405

20. Ballew P, Castro S, Claus J, Kittur N, Brennan L \& Brownson R. Developing web-based training for public health practitioners: what can we learn from a 
review of five disciplines? Health Educ Res 2013; 28: 276-287.

doi:10.1093/her/cys098

21. Miller G. The Smartphone Psychology Manifesto. Perspect Psychol Sci 2012; 7: 221-237. doi: 10.1177/1745691612441215

22. Geraedts AS, Kleiboer AM, Wiezer NM, Cuijpers P, van Mechelen W and Anema JR. Feasibility of a worker-directed web-based intervention for employees with depressive symptoms. Internet Interventions 2014; 1: 132-140. doi: 10.1016/j.invent.2014.07.001

23. Heber E, Ebert DD, Lehr D, et al. Efficacy and cost-effectiveness of a webbased and mobile stress-management intervention for employees: design of a randomized controlled trial. BMC Public Health 2013. doi: 10.1186/14712458-13-655

24. Glasgow RE, Vogt TM and Boles SM. Evaluating the Public Health Impact of Health Promotion Interventions: The RE-AIM Framework. Am J Public Health 1999; 89: 1322-1327. doi: 10.2105/AJPH.89.9.1322

25. Strecher VJ, McClure J, Alexander GL, Chakraborty B, Nair VN, Konkel JM, Greene SM, Collins LM, Carlier CC, Wiese CJ, Roderick JL, Pomerleau C and Pomerleau O. Web-Based Smoking-Cessation Program: Results of a Randomized Trial. Am J Prev Med 2008; 34: 373-381. doi: 10.1016/j.amepre.2007.12.024

26. Glasgow RE, Nelson CC, Kearney KA, Reid R, Ritzwoller DP, Strecher VJ, Couper MP, Green B and Wildenhaus K. Reach, Engagement, and Retention in an Internet-Based Weight Loss Program in a Multi-Site Randomized Controlled Trial. J Med Internet Res 2007; 9: e11. doi: 10.2196/jmir.9.2.e11 
27. Gardner D, Carlopio J, Fonteyn PN and Cross JA. Mechanical Equipment Injuries in Small Manufacturing Businesses. Knowledge, Behavioral, and Management Issues.Int J Occup Saf Ergo 1999; 5: 59-71.

28. Carlbring P, Maurin L, Törngren C, Linna E, Eriksson T, Sparthan E, Straat M, Marquez von Hage C, Bergman-Nordgren L and Andersson G. Individuallytailored, Internet-based treatment for anxiety disorders: A randomized controlled trial. Behav Res Ther 2011; 49: 18-24. doi:

10.1016/j.brat.2010.10.002

29. Highet $\mathrm{N}$ and Culjak G. Are mailouts an effective health promotion strategy? If so, for whom? Int J Ment Health Prom 2014; 14: 13-22. doi: $10.1080 / 14623730.2012 .665340$

30. Gurt J, Schwennen C and Elke G. Health-specific leadership: Is there an association between leader consideration for the health of employees and their strain and well-being? Work Stress 2011; 25: 108-127. doi: $10.1080 / 02678373.2011 .595947$

31. Nöhammer E, Eitzinger C, Schaffenraht-Resi M and Stummer H. Zielgruppenorientierung und betriebliche Gesundheitsförderung [Target Group Orientation and Workplace Health Promotion]. Präv Gesundheitsf 2009; 4: 7782. doi: 10.1007/s11553-008-0154-9

32. Papastathopoulou P and Avlonitis G. Classifying enterprises on the basis of WWW use: a behavioral approach. Internet Res 2009; 19: 332-347. doi: $10.1108 / 10662240910965388$ 


\section{Tables}

Table 1. Questions used in the study.

No. Item Scale

1 Workplace health promotion projects could improve employee health in positive attitude the long run and can make a positive contribution to the companies' towards whp performance.

2 I would wish that health-related problems of employees could be detected in an early phase so that interventions can be initiated.

3 In my opinion, interventions in workplace health promotion can contribute to less sickness absences.

4 An organization has to take responsibility for the health of its employees.

5 There is no point in workplace health promotion, as employees usually are not enthusiastic about workplace health promotion activities. (inv)

6 In our organization, workplace health promotion is not necessary. (inv)

7 I would like to use a new technology (e.g. a smartphone app) to support acceptance of using workplace health promotion projects.

apps in whp

8 With technical help (e.g. a smartphone app) health-relevant aspects can be measured more efficiently.

$9 \quad$ For an adequate feedback, experts are absolutely necessary.

expert-feedback

10 To give professional feedback, trainings would be helpful.

11 Especially for critical feedback, it is important that experts give it.

12 It is an interesting option to give feedback with new media like smartphone apps (e.g. via chat).

feedback from new media

13 Giving feedback indirectly via new technologies is impersonal. (inv)

14 Individual feedback from a smartphone app / a web portal [..] would individual feedback motivate [..] for physical fitness

15 Individual feedback from a smartphone app / a web portal [..] would motivate [..] for mental fitness.

16 Individual feedback from a smartphone app / a web portal [..] would motivate [..] to proceed with healthy nutrition.

17 Analyses of results from a smartphone app / a web portal [..] would motivate [..] for physical fitness. analyses of results

18 Analyses of results from a smartphone app / a web portal [..] would motivate [..] for mental fitness.

19 Analyses of results from a smartphone app / a web portal [..] would motivate [..] to proceed with healthy nutrition.

20 Advices and suggestions from a smartphone app / a web portal [..] would advice/suggestions motivate [..] for physical fitness.

21 Advices and suggestions from a smartphone app / a web portal [..] would motivate [..] for mental fitness.

22 Advices and suggestions from a smartphone app / a web portal [..] would motivate $[.$.$] to proceed with healthy nutrition.$

23 Letting others see my physical training results on a social platform (e.g. sharing results twitter, facebook) [..] would motivate [..] for physical fitness..

24 Letting others see my mental training results on a social platform (e.g. twitter, facebook) [..] would motivate [..] for mental fitness..

25 Letting others see me eating healthy food on a social platform (e.g. twitter, facebook) [...] would motivate [..] to proceed with healthy nutrition. 
Table 2. Means, standard deviations, internal consistencies (Cronbach's $\alpha$ ) and correlations between all study scales.

\begin{tabular}{|c|c|c|c|c|c|c|c|c|c|c|c|c|c|c|c|c|}
\hline No. & Dimension & Mean & SD & $\alpha$ & 1 & 2 & 3 & 4 & 5 & 6 & 7 & 8 & 9 & 10 & 11 & 12 \\
\hline 1 & gender & - & - & - & & & & & & & & & & & & \\
\hline 2 & age & - & - & - & .00 & & & & & & & & & & & \\
\hline 3 & leadership experience & - & - & - & .07 & $.57 *$ & & & & & & & & & & \\
\hline 4 & number of direct subordinates & - & - & - & .02 & -.04 & .06 & & & & & & & & & \\
\hline 5 & size of organization & - & - & - & .09 & -.09 & -.02 & $.66^{*}$ & & & & & & & & \\
\hline 6 & positive attitude towards WHP & 3.83 & 0.81 & .84 & -.02 & $.15^{*}$ & .06 & .05 & $.16^{*}$ & & & & & & & \\
\hline 7 & $\begin{array}{l}\text { Positive acceptance of apps in } \\
\text { WHP }\end{array}$ & 3.11 & 1.08 & .80 & .06 & -.09 & -.02 & .05 & $.11^{+}$ & $.26^{*}$ & & & & & & \\
\hline 8 & expert-feedback & 3.93 & 0.88 & .85 & -.08 & $.16^{*}$ & .09 & -.06 & .03 & $.39 *$ & $.19 *$ & & & & & \\
\hline 9 & feedback from new media & 2.34 & 0.96 & .51 & .05 & $-.13^{+}$ & -.09 & $.10^{+}$ & $.10^{+}$ & $-.16^{*}$ & $.30 *$ & $-.20 *$ & & & & \\
\hline 10 & individual feedback & 2.71 & 1.25 & .95 & .09 & $-.12^{+}$ & -.03 & .08 & $.10^{+}$ & .04 & $.67 *$ & .08 & $.44^{*}$ & & & \\
\hline 11 & analyses of results & 2.77 & 1.25 & .95 & .09 & $-.11^{+}$ & -.03 & .07 & $.11^{+}$ & .07 & $.67 *$ & $.10+$ & $.43 *$ & $.93 *$ & & \\
\hline 12 & advice/suggestions & 2.81 & 1.23 & .95 & .07 & -.09 & -.03 & .09 & $.11^{+}$ & $.13^{*}$ & $.65^{*}$ & $.13 *$ & $.38 *$ & $.87 *$ & $.90^{*}$ & \\
\hline 13 & sharing results & 2.26 & 1.19 & .95 & .05 & $-.16^{*}$ & -.09 & .12 & .07 & -.07 & $.41^{*}$ & -.09 & $.45^{*}$ & $.64 *$ & $.60 *$ & $.60 *$ \\
\hline
\end{tabular}

Note: $\mathrm{N}=438$; Spearman's Rho was calculated for ordinal variables; * correlation significant $(\mathrm{p}<01) ;+$ correlation significant $(\mathrm{p}<05)$ 
Table 3. Results of the multiple regression analyses (standardized regression coefficients from the last step)

\begin{tabular}{|c|c|c|c|c|c|c|c|c|c|c|c|c|c|c|}
\hline & \multicolumn{2}{|c|}{$\begin{array}{c}\text { acceptance of apps } \\
\text { in WHP }\end{array}$} & \multicolumn{2}{|c|}{ expert feedback } & \multicolumn{2}{|c|}{$\begin{array}{l}\text { feedback new } \\
\text { media }\end{array}$} & \multicolumn{2}{|c|}{$\begin{array}{l}\text { individual } \\
\text { feedback }\end{array}$} & \multicolumn{2}{|c|}{ analyses of results } & \multicolumn{2}{|c|}{ advice/suggestions } & \multicolumn{2}{|c|}{ sharing results } \\
\hline & $\beta$ & p-value & $\beta$ & p-value & $\beta$ & p-value & $\beta$ & p-value & $\beta$ & p-value & $\beta$ & p-value & $\beta$ & $\mathrm{p}$-value \\
\hline \multicolumn{15}{|l|}{ Step 1: individual aspects } \\
\hline gender (male) & .06 & .207 & -.07 & .116 & .04 & .433 & .08 & .086 & .09 & .068 & .07 & .155 & .04 & .372 \\
\hline age & $-.14 * *$ & .003 & $.12 *$ & .010 & -.09 & .072 & $-.11 *$ & .022 & $-.11 *$ & .024 & $-.10 *$ & .035 & $-.14 *$ & .003 \\
\hline leadership experience & .00 & .948 & .04 & .466 & -.03 & .539 & -04 & .511 & -.02 & .676 & .02 & .737 & -.02 & .683 \\
\hline positive attitude towards WHP & $.27 * *$ & $<.001$ & $.38 * *$ & $<.001$ & $-.17 * *$ & $<.000$ & .05 & .356 & .07 & .129 & $.14 * *$ & .005 & -.05 & .309 \\
\hline \multicolumn{15}{|l|}{ Step 2: organizational aspects } \\
\hline number of direct subordinates & .03 & .667 & -.08 & .143 & .04 & .547 & .06 & .366 & .03 & .638 & .06 & .353 & .12 & .056 \\
\hline size of organization & .03 & .612 & .07 & .300 & .07 & .291 & .06 & .419 & .07 & .283 & .04 & .563 & .00 & .954 \\
\hline Model $\mathrm{R}^{2}$ adjusted & .08 & & .17 & & .04 & & .02 & & .02 & & .02 & & .02 & \\
\hline
\end{tabular}

Note: **correlation significant $(\mathrm{p}<.01) ; *$ correlation significant $(\mathrm{p}<.05)$ 
Using smartphone-based applications 25 